OPEN ACCESS

Edited by: Takahiro A. Kato,

Kyushu University, Japan

Reviewed by:

Andrew MacLean,

Tulane University School of Medicine,

Mohan Pabba

Center for Addiction and

Mental Health, Canada

*Correspondence:

Leanne Stokes,

School of Pharmacy, University of East Anglia, Norwich Research Park,

Norwich, NR4 7TJ, UK

l.stokes@uea.ac.uk

Received: 25 March 2015 Accepted: 22 June 2015 Published: 08 July 2015

Citation:

Stokes L, Spencer SJ and Jenkins TA

(2015) Understanding the role of P2X7 in affective disorders - are glial cells the major players?

Front. Cell. Neurosci. 9:258

doi: 10.3389/fncel.2015.00258

\section{Understanding the role of P2X7 in affective disorders-are glial cells the major players?}

\author{
Leanne Stokes ${ }^{1,2 *}$, Sarah J. Spencer ${ }^{3}$ and Trisha A. Jenkins ${ }^{1}$ \\ ${ }^{1}$ School of Medical Sciences, Health Innovations Research Institute, RMIT University, Melbourne, VIC, Australia, ${ }^{2}$ School of \\ Pharmacy, University of East Anglia, Norwich, UK, ${ }^{3}$ School of Health Sciences, Health Innovations Research Institute, RMIT \\ University, Melbourne, VIC, Australia
}

Pathophysiology associated with several psychiatric disorders has been linked to inflammatory biomarkers. This has generated a theory of major depressive disorders as an inflammatory disease. The idea of pro-inflammatory cytokines altering behavior is now well accepted however many questions remain. Microglia can produce a plethora of inflammatory cytokines and these cells appear to be critical in the link between inflammatory changes and depressive disorders. Microglia play a known role in sickness behavior which has many components of depressive-like behavior such as social withdrawal, sleep alterations, and anorexia. Numerous candidate genes have been identified for psychiatric disorders in the last decade. Single nucleotide polymorphisms (SNPs) in the human P2X7 gene have been linked to bipolar disorder, depression, and to the severity of depressive symptoms. P2X7 is a ligand-gated cation channel expressed on microglia with lower levels found on astrocytes and on some neuronal populations. In microglia P2X7 is a major regulator of pro-inflammatory cytokines of the interleukin-1 family. Genetic deletion of P2X7 in mice is protective for depressive behavior in addition to inflammatory responses. P2X7-/- mice have been shown to demonstrate anti-depressive-like behavior in forced swim and tail suspension behavioral tests and stressor-induced behavioral responses were blunted. Both neurochemical (norepinephrine, serotonin, and dopamine) and inflammatory changes have been observed in the brains of $\mathrm{P} 2 \mathrm{X} 7^{-1-}$ mice. This review will discuss the recent evidence for involvement of P2X7 in the pathophysiology of depressive disorders and propose mechanisms by which altered signaling through this ion channel may affect the inflammatory state of the brain.

Keywords: P2X7, depression, microglia, inflammation, mouse models, SNP

\section{Inflammation as a Theory for Pathogenesis of Mood-Related Behavioral Changes}

Recent evidence suggests that activation of inflammatory responses may contribute to the pathogenesis of affective disorders such as depression, bipolar disorders and schizophrenia. Results from studies of clinical psychosis indicate high levels of pro-inflammatory macrophagederived cytokines in both serum and plasma in psychotic relative to normal patients. Much of the available research to date has focused on circulating levels of pro-inflammatory agents, 
including the key interleukins (particularly IL-6, IL-2, IL-1 $\beta$ ), tumor necrosis factor (TNF- $\alpha$ ) and its receptors, and interferon gamma (IFN- $\gamma$ ) in schizophrenia (Gaughran, 2002; Drzyzga et al., 2006), bipolar disorder (O'Brien et al., 2006; Hope et al., 2009) and depression (Hiles et al., 2012; Liu et al., 2012; Dahl et al., 2014). However there is also increasing evidence of inflammatory cytokines and activation of microglia in the brains of affective disorder subjects. In schizophrenic patients elevated levels of IL-6 (Garver et al., 2003; Sasayama et al., 2013) and IL-1 $\beta$ cytokines (Miller et al., 2011) have been observed in cerebrospinal fluid (CSF); while in bipolar disorder an increase in IL-1 $\beta$ in the CSF of patients was recently found (Söderlund et al., 2011). Cytokines, in turn, promote detrimental neuronal consequences through activation of neuroinflammatory cascades involving microglial release of oxidative species. Several post-mortem studies have reported an increased density of microglia in the hippocampus (Bayer et al., 1999) and regions of the prefrontal, cingulate and temporal cortices (Bayer et al., 1999; Radewicz et al., 2000; Steiner et al., 2008). Indeed, imaging and histological studies also report increased levels astrocyte and microglial markers (e.g., glial fibrillary acidic protein, GFAP, CD11b) in the prefrontal cortex (Rao et al., 2010) and hippocampus (Haarman et al., 2014) in bipolar patients and increased microglial priming and macrophage recruitment in the cingulate cortex of depressed brains (Torres-Platas et al., 2014). Moreover, in CSF collected from depressive patients, increases in inflammatory mediators, such as kynurenine and quinolinic acid released from microglia, are correlated with increased IFN- $\alpha$, soluble TNF- $\alpha$ receptor 2 and the chemokine monocyte chemo-attractant protein (MCP-1) in CSF (Raison et al., 2010). While there should also be consideration of the external influence of medications (lithium, antidepressants antipsychotics), age, and patient health status (such as metabolic syndrome or chronic pain) which can all have their own inflammatory influences, it is still clear that elevated immuneinflammatory signaling activity is important in the etiology of mood disorders.

\section{Sickness Behavior; Inflammation-Related Behavioral Changes}

The origin of pro-inflammatory cytokines found in the brain is yet to be clearly elucidated. While cytokines can be produced centrally, it is also of consideration that they are released by circulating immune cells and move to the brain through specific transport mechanisms such as via the circumventricular organs or across a dysfunctioning blood brain barrier. Evidence from animal studies indeed show that activation of the peripheral immune system influences brain pathology, cytokine levels, and behavior. Exposure to the bacterial endotoxin lipopolysaccharide (LPS) or the viral immunostimulant polyinosinic: polycytidylic acid (poly I:C) can induce sickness behavior, a depressive-like state where reductions in food consumption, body weight, social interaction and activity are observed (Yirmiya, 1996; Cunningham et al., 2007). This so-called sickness behavior is both a physical and psychological illness and is observed in humans, encompassing such complications as fatigue, lethargy, anhedonia, anorexia, and muscle and joint pain (Dantzer, 2009). Triggered by the production of pro-inflammatory cytokines by the immune system, it is thought to be part of a highly organized strategy to fight infections.

There are several glial (non-neuronal) cell populations in the brain, notably astrocytes, microglia and oligodendrocytes. The activation of brain microglia has been associated with depressive-like behavior in a number of recent studies (Tynan et al., 2010; Hinwood et al., 2012; Kreisel et al., 2014). In many cases psychological stress induced through prolonged restraint or unpredictable events, is demonstrated to alter microglial responses upregulating various cellular activation markers such as Iba-1, CD11b, and MHC Class II. The number and density of microglia in particular brain regions appears to be altered on the same time-scale as the behavioral changes. Dynamic changes in both number and activation status of microglia have been recently documented with acute increases in microglial number followed by a decline in number with more sustained (chronic) stress (Kreisel et al., 2014). Potentially, this early increased density of activated microglia could amplify proinflammatory signaling through the release of inflammatory and neurotoxic mediators such as cytokines. Blocking the initial activation with minocycline rescued the decline in microglial numbers and the behavioral change (Kreisel et al., 2014).

\section{P2X7 is an lon Channel Regulating Inflammatory Signaling}

$\mathrm{P} 2 \mathrm{X} 7$ is a purinergic ion channel activated by the known danger signal molecule and neurotransmitter, ATP (Bartlett et al., 2014). Many immune cells express this purinergic ion channel including myeloid lineage cells such as macrophages and their brain-resident counterparts, microglia. P2X7 expression is not restricted to microglia in the brain, with astrocytes, oligodendrocytes and certain populations of neurons exhibiting low levels of expression (reviewed in Bartlett et al., 2014). Over the last decade research into understanding the role of this ion channel in immune cell responses has revealed a critical function in the regulation of cytokine secretion from macrophages and microglia. It is clear that activation of $\mathrm{P} 2 \mathrm{X} 7$ is a major physiological stimulus for rapid secretion of IL-1 family cytokines from macrophages and microglia (Ferrari et al., 1997, 2006). Evidence for involvement of P2X7 activation in regulating other pro-inflammatory cytokine secretion is less robust although there is evidence for a role in IL-6 secretion from macrophages (Solle et al., 2001) and both TNF- $\alpha$ and IL-6 secretion from microglia (Shieh et al., 2014). In addition to cytokines $\mathrm{P} 2 \mathrm{X} 7$ is involved in inflammatory prostaglandin secretion (Barberà-Cremades et al., 2012) and release of lysosomal proteases such as cathepsins (Lopez-Castejon et al., 2010).

Transgenic mice deficient in $\mathrm{P} 2 \mathrm{X} 7\left(\mathrm{P} 2 \mathrm{X}^{-/-}\right)$were generated over a decade ago and have aided our understanding of the physiological and pathophysiological roles of this ion channel. 
$\mathrm{P} 2 \mathrm{X}^{-/-}$mice were originally demonstrated to display reduced cytokine responses (Solle et al., 2001) and subsequent studies have documented reduced inflammatory-related disorders such as anti-collagen induced arthritis (Labasi et al., 2002). Ex vivo macrophages isolated from $\mathrm{P} 2 \mathrm{X}^{-/-}$mice display no secretion of IL-1 $\beta$, IL-18 and IL- $1 \alpha$ cytokines in response to in vitro priming and challenge with ATP (Pelegrin et al., 2008). Furthermore, intraperitoneal injection of LPS into $\mathrm{P} 2 \mathrm{X} 7^{-/-}$ mice caused a reduced febrile response compared to wildtype mice, which was restored upon injection of recombinant IL-1 $\beta$ (Barberà-Cremades et al., 2012). This suggests that P2X7-induced IL-1 $\beta$ secretion plays a key pyrogenic role in vivo. The behavioral effects of injected LPS were not investigated by Barberà-Cremades et al. (2012), however a separate study by Csölle et al. (2013b) has demonstrated that LPS-induced anhedonia measured using a sucrose preference test is reduced in $\mathrm{P} 2 \mathrm{X} 7^{-/-}$mice. These studies suggest that inflammatory responses to LPS are reduced in P2X7 deficient mice.

\section{P2X7 and Microglial Responses}

Early studies demonstrated that activation of P2X7 stimulated IL-1 $\beta$ cytokine release from mouse microglial cells (Ferrari et al., 1997). Experiments utilizing P2X7 ${ }^{-/-}$mice demonstrated that P2X7 was crucial for ATP-mediated IL- $1 \beta$ release from microglia and that P2X7 deficiency attenuated LPS-induced expression of both IL-1 $\beta$ and TNF $\alpha$ (Mingam et al., 2008). In addition to control of cytokines, P2X7 on microglial cells has been linked to glial cytotoxicity, with the induction of apoptotic cell death following prolonged stimulation (Bartlett et al., 2013). P2X7 on microglia can also induce cortical neuron cell injury in a co-culture model system, using a process not requiring direct cellular contact (Skaper et al., 2006). Microglia deficient in P2X7 or treated with a P2X7 antagonist did not induce neuronal toxicity in this study highlighting a key role for this ion channel in secreting mediators capable of reducing neuronal viability (Skaper et al., 2006).

More recently $\mathrm{P} 2 \mathrm{X} 7$ has been implicated in cellular proliferative responses in microglia amongst other cell types, with a study reporting that overexpression of P2X7 was sufficient to drive proliferation and activation of microglia (Monif et al., 2009). These observations are complemented by a study investigating basal and TNF $\alpha$ cytokine-induced proliferation in hippocampal-entorhinal slices where P2X7 was demonstrated to play a key role in proliferation (Zou et al., 2012). The involvement of P2X7 in microglial responses is summarized in Figure 1.

\section{P2X7 Deficient Mice are Resilient to Depressive-like Behavior}

Four studies by different groups have so far investigated the effect of genetic deletion of P2X7 on behavior using standard depression tests in mice, namely the forced swim test and tail suspension test. All four studies demonstrated

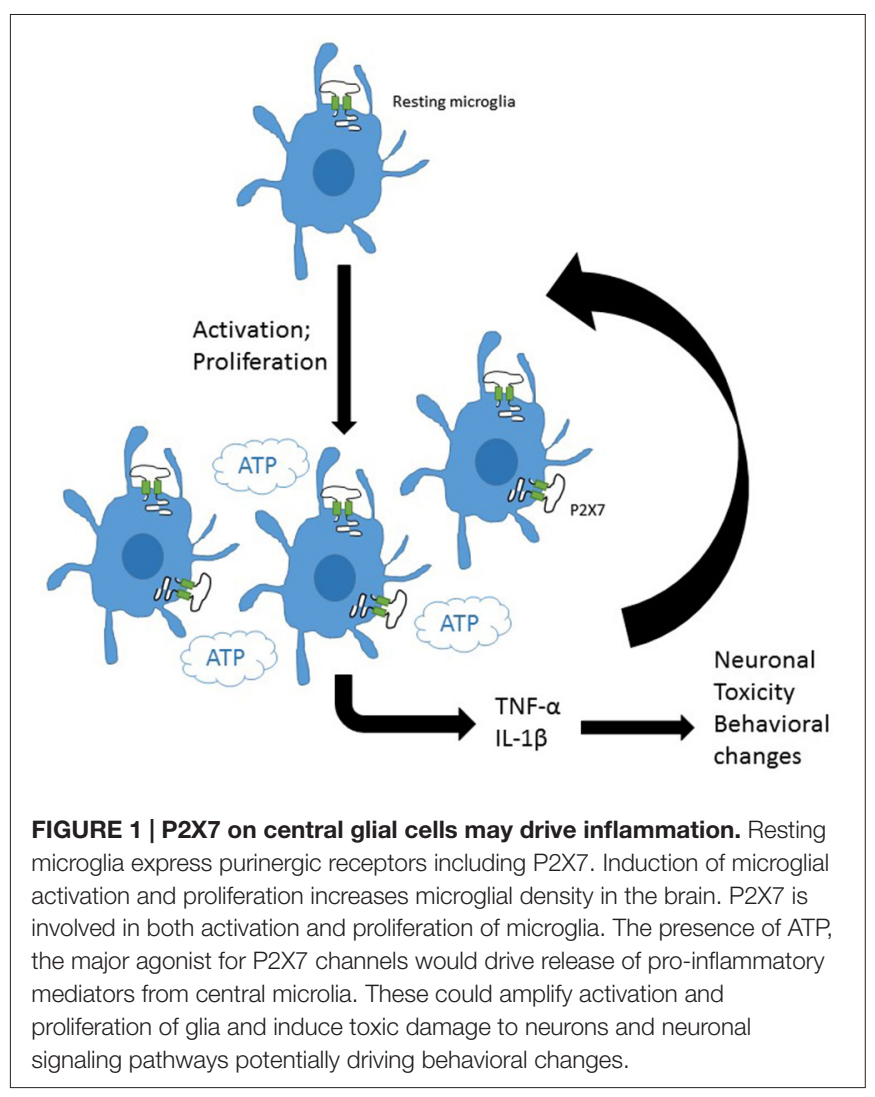

a significant reduction in immobility time in $\mathrm{P} 2 \mathrm{X} 7^{-/-}$mice, a feature associated with anti-depressive behavior (Basso et al., 2009; Boucher et al., 2011; Csölle et al., 2013a,b). Differences between genotypes were more obvious after repeated challenge or stress suggesting that the demonstrated resilience is more pronounced to stressor-induced behavioral changes. Pharmacological blockade of P2X7 was also effective in altering depressive-like behavior and LPS-induced sickness behavior in mice (Csölle et al., 2013a,b). Selective, centrally penetrating P2X7 modulators may have potential for further development as therapies for CNS disorders including affective disorders. Three P2X7 antagonists A-438079, JNJ-47965567, and JNJ-42253432, have recently been demonstrated to attenuate amphetamineinduced behavioral sensitization in rodents (Bhattacharya et al., 2013; Gubert et al., 2014; Lord et al., 2014), a key process underlying motivational behavior. Moreover antidepressant and anxiolytic like behavior is observed after P2X7 antagonism in animal models exhibiting depressive-like symptomatology in forced swim and social interaction paradigms (Pereira et al., 2013; Lord et al., 2014; Wilkinson et al., 2014).

A major finding from the work by Csölle et al. (2013a) was that peripheral immune cells such as infiltrating monocytes or macrophages do not appear to be involved in protection from depressive behavior associated with P2X7 deficiency. To demonstrate this they used bone marrow chimera experiments. Here mice were irradiated to destroy circulating immune cells and underwent a bone marrow transplant from donor mice which were either wild-type $(\mathrm{P} 2 \mathrm{X} 7+)$ or knockout $(\mathrm{P} 2 \mathrm{X} 7-)$. 
Reconstituted mice with both P2X7 expressing and P2X7 deficient bone marrow demonstrated no difference in immobility time in the tail suspension test. The study concluded that deficiency of P2X7 only in peripheral immune cells gave no protection from depressive-like behavior (Csölle et al., 2013a). Whilst this study also suggested central microglia were not involved through the same bone marrow chimera approach, more data would be helpful to strengthen this particular conclusion. For example, does central injection of IL-1 $\beta$ restore depressive-like behavior in the $\mathrm{P} 2 \mathrm{X} 7^{-/-}$mouse? This would indicate whether cytokines were driving depressive behavior. In addition, these behavioral studies use C57BL/6 mice which are known to carry a single nucleotide polymorphism (SNP) in the C-terminus of P2X7 affecting downstream signaling pathways including cytokine secretion (Adriouch et al., 2002). It would be interesting and relevant to determine if this effect is maintained in mouse strains carrying a high functioning P2X7.

Significant differences in expression (both up- and downregulation) of genes involved in synaptic signaling were found by whole genome microarrays in the amygdala of $\mathrm{P} 2 \mathrm{X}^{-/-}$ mice (Csölle et al., 2013a). Moreover, exposure to restraint stress caused an acute elevation in adrenocorticotropic hormone (ACTH) and corticosterone levels in wild-type C57BL/6 mice but this was reduced in $\mathrm{P} 2 \mathrm{X} 7^{-/-}$mice (Csölle et al., 2013a). This suggests that P2X7 deficiency may blunt the stress hormone response. The anterior pituitary, which is responsible for the production of stress hormones amongst others, expresses P2X channels (Koshimizu et al., 2000; Zemkova et al., 2006) and ATP is known to modulate ACTH secretion. Therefore it is possible $\mathrm{P} 2 \mathrm{X} 7$ may play a role in the amplification of secretagogue signals from the hypothalamus.

\section{A Mutant P2X7 Allele Linked to Depression and Bipolar Disorder in Human Studies}

There have been a number of genetic studies over the last decade linking a SNP in the human $P 2 R X 7$ gene to depression, anxiety, and bipolar disorder (Barden et al., 2006; Lucae et al., 2006; McQuillin et al., 2009; Soronen et al., 2011). Inheritance of the minor allele of this SNP (rs2230912-G) has also been correlated to severity of depression in diabetic and psychiatric patients (Hejjas et al., 2009; Nagy et al., 2008; Halmai et al., 2013). In contrast there are several genetic studies that do not find an association with $P 2 R X 7$ genotype at this polymorphic site and bipolar disorder, major depression or schizophrenia (Green et al., 2009; Viikki et al., 2011). A recent meta-analysis also suggested no association (Feng et al., 2014). Addressing the functional relevance of this SNP in vitro studies on circulating immune cells isolated from humans carrying the rs2230912-G allele have demonstrated that this genetic variant of P2X7 is inherited on a gain-of-function allele (Stokes et al., 2010). Importantly human monocytes expressing this rs $2230912-\mathrm{G}$ variant secreted more IL-1 $\beta$ in response to activation of P2X7 than monocytes expressing a wild-type variant (Stokes et al., 2010). Therefore one could speculate that microglia in the brain may also display enhanced cytokine secretion in response to P2X7 ion channel activation. Whilst this is difficult to demonstrate in the human system, a transgenic mouse approach knockingin this human variant of P2X7 could begin to address this question.

In transgenic mouse studies genetic deletion of $\mathrm{P} 2 \mathrm{X} 7$ eliminates a full-length P2X7 protein and protects against depressive learned helplessness behavior (Basso et al., 2009; Boucher et al., 2011; Csölle et al., 2013a). Could this also be true for humans? There are numerous loss-of-function SNPs in the human P2X7 gene which are demonstrated to have dramatic effects on receptor trafficking or receptor function (Sluyter and Stokes, 2011). Several studies have included some (but not all) loss-of-function P2X7 SNPs in their analysis but no difference in genotype frequency has so far been documented (Barden et al., 2006; Hansen et al., 2008).

\section{The Gliotransmitter ATP and Depressive Behavior}

The purinergic signaling system is extensive in the body involving many receptors, ion channels and enzymes. ATP is a known co-transmitter released at synapses and extrasynaptic sites modulating the responses of glial and neurons (Burnstock, 2008). A recent study by Cao et al. presents a novel case for astrocyte-derived ATP as a rapid anti-depressant neurotransmitter (Cao et al., 2013). But how does this idea fit with a role for P2X7 (and potentially other purinergic receptors) in depressive disorders? Cao et al. (2013) suggest that astrocytes release ATP in the medial prefrontal cortex where the P2X2 receptor seems to be the downstream target for this anti-depressant action of ATP as evidenced by shRNA experiments. Astrocytes and microglia both express P2X7, which can be activated by relatively high concentrations of ATP $(>100 \mu \mathrm{M})$; levels that may not be achieved in the brain where nucleotidases are widely expressed (Robson et al., 2006). Thus astrocyte-derived ATP may not reach concentrations high enough to stimulate pro-inflammatory signaling through P2X7. In $\mathrm{P} 2 \mathrm{X}^{-/-}$mice, which demonstrate an antidepressant-like phenotype, Csölle et al. (2013a) demonstrated an up-regulation of a number of genes in the amygdala including P2RX2 (11fold change). Together with the evidence that immune cells (including microglia) do not affect the behavioral phenotype, perhaps this highlights a role for astrocytes, ATP, and P2X2, in the antidepressant effect of P2X7 deficiency? It is clear that more studies are required to understand the role of purinergic signaling in psychiatric disorders.

\section{Future Perspectives}

In humans a correlation between high functioning P2X7 and affective disorders is often observed but this may be limited to patients with an inflammatory component, for example diabetic patients. Perhaps understanding more about the clinical features associated with affective disorders will lead to a useful stratification of these disorders and co-morbidity with other diseases. The evidence for involvement of P2X7 in depressive disorders from animal studies is promising but it is clear 
that more information about this ion channel and its role in inflammation and behavior is needed. Microglia are known to play a role in stress-induced depressive behavior but is P2X7 a major driver of inflammatory signaling in central microglia under conditions of chronic stress? P2X7 is not restricted

\section{References}

Adriouch, S., Dox, C., Welge, V., Seman, M., Koch-Nolte, F., and Haag, F. (2002). Cutting edge: a natural P451L mutation in the cytoplasmic domain impairs the function of the mouse P2X7 receptor. J. Immunol. 169, 4108-4112. doi: 10. 4049/jimmunol.169.8.4108

Barberà-Cremades, M., Baroja-Mazo, A., Gomez, A. I., Machado, F., Di Virgilio, F., and Pelegrin, P. (2012). P2X7 receptor-stimulation causes fever via PGE2 and IL-1beta release. FASEB J. 26, 2951-2962. doi: 10.1096/fj.12205765

Barden, N., Harvey, M., Gagné, B., Shink, E., Tremblay, M., Raymond, C., et al. (2006). Analysis of single nucleotide polymorphisms in genes in the chromosome 12Q24.31 region points to P2RX7 as a susceptibility gene to bipolar affective disorder. Am. J. Med. Genet. B Neuropsychiatr. Genet. 141B, 374-382. doi: 10.1002/ajmg.b.30303

Bartlett, R., Stokes, L., and Sluyter, R. (2014). The P2X7 receptor channel: recent developments and the use of P2X7 antagonists in models of disease. Pharmacol. Rev. 66, 638-675. doi: 10.1124/pr.113.008003

Bartlett, R., Yerbury, J. J., and Sluyter, R. (2013). P2X7 receptor activation induces reactive oxygen species formation and cell death in murine EOC13 microglia. Mediators Inflamm. 2013:271813. doi: 10.1155/2013/271813

Basso, A., Bratcher, N., Harris, R., Jarvis, M., Decker, M., and Rueter, L. (2009). Behavioral profile of P2X7 receptor knockout mice in animal models of depression, anxiety: relevance for neuropsychiatric disorders. Behav. Brain Res. 198, 83-90. doi: 10.1016/j.bbr.2008.10.018

Bayer, T. A., Buslei, R., Havas, L., and Falkai, P. (1999). Evidence for activation of microglia in patients with psychiatric illnesses. Neurosci. Lett. 271, 126-128. doi: 10.1016/s0304-3940(99)00545-5

Bhattacharya, A., Wang, Q., Ao, H., Shoblock, J. R., Lord, B., Aluisio, L., et al. (2013). Pharmacological characterization of a novel centrally permeable P2X7 receptor antagonist: JNJ-47965567. Br. J. Pharmacol. 170, 624-640. doi: 10. 1111/bph.12314

Boucher, A. A., Arnold, J. C., Hunt, G. E., Spiro, A., Spencer, J., Brown, C., et al. (2011). Resilience and reduced c-Fos expression in P2X7 receptor knockout mice exposed to repeated forced swim test. Neuroscience 189, 170-177. doi: 10 . 1016/j.neuroscience.2011.05.049

Burnstock, G. (2008). Purinergic signalling and disorders of the central nervous system. Nat. Rev. Drug Discov. 7, 575-590. doi: 10.1038/nrd2605

Cao, X., Li, L.-P., Wang, Q., Wu, Q., Hu, H.-H., Zhang, M., et al. (2013). Astrocytederived ATP modulates depressive-like behaviors. Nat. Med. 19, 773-777. doi: $10.1038 / \mathrm{nm} .3162$

Csölle, C., Andó, R., Kittel, Å., Gölöncsér, F., Baranyi, M., Soproni, K., et al. (2013a). The absence of P2X7 receptors (P2rx7) on non-haematopoietic cells leads to selective alteration in mood-related behaviour with dysregulated gene expression and stress reactivity in mice. Int. J. Neuropsychopharmacol. 16, 213-233. doi: 10.1017/s1461145711001933

Csölle, C., Baranyi, M., Zsilla, G., Kittel, Á., Gölöncsér, F., Illes, P., et al. (2013b). Neurochemical changes in the mouse hippocampus underlying the antidepressant effect of genetic deletion of P2X7 receptors. PLoS One 8:e66547. doi: 10.1371/journal.pone.0066547

Cunningham, C., Campion, S., Teeling, J., Felton, L., and Perry, V. H. (2007). The sickness behaviour and CNS inflammatory mediator profile induced by systemic challenge of mice with synthetic double-stranded RNA (poly I:C). Brain Behav. Immun. 21, 490-502. doi: 10.1016/j.bbi.2006.12.007

Dahl, J., Ormstad, H., Aass, H. C., Malt, U. F., Bendz, L. T., Sandvik, L., et al. (2014). The plasma levels of various cytokines are increased during ongoing depression and are reduced to normal levels after recovery. Psychoneuroendocrinology 45, 77-86. doi: 10.1016/j.psyneuen.2014.03.019

Dantzer, R. (2009). Cytokine, sickness behavior and depression. Immunol. Allergy Clin. North Am. 29, 247-264. doi: 10.1016/j.iac.2009.02.002 to microglia and it is likely that astrocytes participate in regulation of microglial and neuronal responses. Future studies will hopefully address these issues and begin to determine whether this ion channel could be a novel drug target for affective disorders.

Drzyzga, L., Obuchowicz, E., Marcinowska, A., and Herman, Z. S. (2006). Cytokines in schizophrenia and the effects of antipsychotic drugs. Brain Behav. Immun. 20, 532-545. doi: 10.1016/j.bbi.2006.02.002

Feng, W.-P., Zhang, B., Li, W., and Liu, J. (2014). Lack of association of P2RX7 gene rs2230912 polymorphism with mood disorders: a meta-analysis. PLoS One 9:e88575. doi: 10.1371/journal.pone.0088575

Ferrari, D., Chiozzi, P., Falzoni, S., Hanau, S., and Di Virgilio, F. (1997). Purinergic modulation of interleukin-1 beta release from microglial cells stimulated with bacterial endotoxin. J. Exp. Med. 185, 579-582. doi: 10.1084/jem.185.3.579

Ferrari, D., Pizzirani, C., Adinolfi, E., Lemoli, R. M., Curti, A., Idzko, M., et al. (2006). The P2X7 receptor: a key player in IL-1 processing and release. $J$ Immunol. 176, 3877-3883. doi: 10.4049/jimmunol.176.7.3877

Garver, D. L., Tamas, R. L., and Holcomb, J. A. (2003). Elevated interleukin6 in the cerebrospinal fluid of a previously delineated schizophrenia subtype. Neuropsychopharmacology 28, 1515-1520. doi: 10.1038/sj.npp. 1300217

Gaughran, F. (2002). Immunity and schizophrenia: autoimmunity, cytokines and immune responses. Int. Rev. Neurobiol. 52, 275-302. doi: 10.1016/s00747742(02)52013-4

Green, E. K., Grozeva, D., Raybould, R., Elvidge, G., Macgregor, S., Craig, I., et al. (2009). P2RX7: a bipolar and unipolar disorder candidate susceptibility gene? Am. J. Med. Genet. B Neuropsychiatr. Genet. 150B, 1063-1069. doi: 10. 1002/ajmg.b.30931

Gubert, C., Fries, G., Pfaffenseller, B., Ferrari, P., Coutinho-Silva, R., Morrone, F., et al. (2014). Role of P2X7 receptor in an animal model of mania induced by DAmphetamine. Mol. Neurobiol. doi: 10.1007/s12035-014-9031-z [Epub ahead of print].

Haarman, B., Doorduin, J., Riemersma-Van Der Lek, R. F., Zandstra, T. E., Drexhage, H. A., and Nolen, W. A. (2014). Neuroinflammation in bipolar disorder? An [11c] PK11195 PET study in euthymic patients. Bipolar Disord. 16, 42-42. doi: 10.1016/j.bbi.2014.03.016

Halmai, Z., Dome, P., Vereczkei, A., Abdul-Rahman, O., Szekely, A., Gonda, X., et al. (2013). Associations between depression severity and purinergic receptor P2RX7 gene polymorphisms. J. Affect. Disord. 150, 104-109. doi: 10.1016/j.jad. 2013.02.033

Hansen, T., Jakobsen, K. D., Fenger, M., Nielsen, J., Krane, K., Fink-Jensen, A., et al. (2008). Variation in the purinergic P2RX7 receptor gene and schizophrenia. Schizophr. Res. 104, 146-152. doi: 10.1016/j.schres.2008.05.026

Hejjas, K., Szekely, A., Domotor, E., Halmai, Z., Balogh, G., Schilling, B., et al. (2009). Association between depression and the Gln460Arg polymorphism of P2RX7 gene: a dimensional approach. Am. J. Med. Genet. B Neuropsychiatr. Genet. 150B, 295-299. doi: 10.1002/ajmg.b.30799

Hiles, S. A., Baker, A. L., de Malmanche, T., and Attia, J. (2012). A meta-analysis of differences in IL- 6 and IL-10 between people with and without depression: exploring the causes of heterogeneity. Brain Behav. Immun. 26, 1180-1188. doi: 10.1016/j.bbi.2012.06.001

Hinwood, M., Morandini, J., Day, T. A., and Walker, F. R. (2012). Evidence that microglia mediate the neurobiological effects of chronic psychological stress on the medial prefrontal cortex. Cereb. Cortex 22, 1442-1454. doi: 10. 1093/cercor/bhr229

Hope, S., Melle, I., Aukrust, P., Steen, N. E., Birkenaes, A. B., Lorentzen, S., et al. (2009). Similar immune profile in bipolar disorder and schizophrenia: selective increase in soluble tumor necrosis factor receptor I and von Willebrand factor. Bipolar Disord. 11, 726-734. doi: 10.1111/j.1399-5618.2009.00757.x

Koshimizu, T.-A., Van Goor, F., Tomić, M., Wong, A. O.-L., Tanoue, A., Tsujimoto, G., et al. (2000). Characterization of calcium signaling by purinergic receptor-channels expressed in excitable cells. Mol. Pharmacol. 58, 936-945. doi: $10.1124 / \mathrm{mol} .58 .5 .936$

Kreisel, T., Frank, M. G., Licht, T., Reshef, R., Ben-Menachem-Zidon, O., Baratta, M. V., et al. (2014). Dynamic microglial alterations underlie 
stress-induced depressive-like behavior and suppressed neurogenesis. Mol. Psychiatry 19, 699-709. doi: 10.1038/mp.2013.155

Labasi, J. M., Petrushova, N., Donovan, C., McCurdy, S., Lira, P., Payette, M. M., et al. (2002). Absence of the P2X7 receptor alters leukocyte function and attenuates an inflammatory response. J. Immunol. 168, 6436-6445. doi: 10. 4049/jimmunol.168.12.6436

Liu, Y., Ho, R. C. M., and Mak, A. (2012). Interleukin (IL)-6, tumour necrosis factor alpha (TNF- $\alpha$ ) and soluble interleukin-2 receptors (sIL-2R) are elevated in patients with major depressive disorder: a meta-analysis and metaregression. J. Affect. Disord. 139, 230-239. doi: 10.1016/j.jad.2011.08.003

Lopez-Castejon, G., Theaker, J., Pelegrin, P., Clifton, A. D., Braddock, M., and Surprenant, A. (2010). P2X7 receptor-mediated release of cathepsins from macrophages is a cytokine-independent mechanism potentially involved in joint diseases. J. Immunol. 185, 2611-2619. doi: 10.4049/jimmunol.1000436

Lord, B., Aluisio, L., Shoblock, J. R., Neff, R. A., Varlinskaya, E. I., Ceusters, M., et al. (2014). Pharmacology of a novel central nervous system-penetrant P2X7 antagonist JNJ-42253432. J. Pharmacol. Exp. Ther. 351, 628-641. doi: 10. 1124/jpet.114.218487

Lucae, S., Salyakina, D., Barden, N., Harvey, M., Gagné, B., Labbé, M., et al. (2006). P2RX7, a gene coding for a purinergic ligand-gated ion channel, is associated with major depressive disorder. Hum. Mol. Genet. 15, 2438-2445. doi: 10. 1093/hmg/ddl166

McQuillin, A., Bass, N., Choudhury, K., Puri, V., Kosmin, M., Lawrence, J., et al. (2009). Case-control studies show that a non-conservative amino-acid change from a glutamine to arginine in the $\mathrm{P} 2 \mathrm{RX} 7$ purinergic receptor protein is associated with both bipolar- and unipolar-affective disorders. Mol. Psychiatry 14, 614-620. doi: 10.1038/mp.2008.6

Miller, B. J., Buckley, P., Seabolt, W., Mellor, A., and Kirkpatrick, B. (2011). Meta-analysis of cytokine alterations in schizophrenia: clinical status and antipsychotic effects. Biol. Psychiatry 70, 663-671. doi: 10.1016/j.biopsych. 2011.04.013

Mingam, R., De Smedt, V., Amédée, T., Bluthé, R.-M., Kelley, K. W., Dantzer, R., et al. (2008). In vitro and in vivo evidence for a role of the $\mathrm{P} 2 \mathrm{X} 7$ receptor in the release of IL-1 $\beta$ in the murine brain. Brain Behav. Immun. 22, 234-244. doi: 10. 1016/j.bbi.2007.08.007

Monif, M., Reid, C., Powell, K., Smart, M., and Williams, D. (2009). The P2X7 receptor drives microglial activation and proliferation: a trophic role for P2X7R pore. J. Neurosci. 29, 3781-3791. doi: 10.1523/JNEUROSCI.5512-08.2009

Nagy, G., Ronai, Z., Somogyi, A., Sasvari-Szekely, M., Rahman, O., Mate, A., et al. (2008). P2RX7 Gln460Arg polymorphism is associated with depression among diabetic patients. Prog. Neuropsychopharmacol. Biol. Psychiatry 32, 1884-1888. doi: 10.1016/j.pnpbp.2008.08.021

O'Brien, S. M., Scully, P., Scott, L. V., and Dinan, T. G. (2006). Cytokine profiles in bipolar affective disorder: focus on acutely ill patients. J. Affect. Disord. 90, 263-267. doi: 10.1016/j.jad.2005.11.015

Pelegrin, P., Barroso-Gutierrez, C., and Surprenant, A. (2008). P2X7 receptor differentially couples to distinct release pathways for IL-1 $\beta$ in mouse macrophage. J. Immunol. 180, 7147-7157. doi: 10.4049/jimmunol.180.11.7147

Pereira, V. S., Casarotto, P. C., Hiroaki-Sato, V. A., Sartim, A. G., Guimarães, F. S., and Joca, S. R. L. (2013). Antidepressant- and anticompulsive-like effects of purinergic receptor blockade: involvement of nitric oxide. Eur. Neuropsychopharmacol. 23, 1769-1778. doi: 10.1016/j.euroneuro.2013.01.008

Radewicz, K., Garey, L. J., Gentleman, S. M., and Reynolds, R. (2000). Increase in HLA-DR immunoreactive microglia in frontal and temporal cortex of chronic schizophrenics. J. Neuropathol. Exp. Neurol. 59, 137-150.

Raison, C. L., Dantzer, R., Kelley, K. W., Lawson, M. A., Woolwine, B. J., Vogt, G., et al. (2010). CSF concentrations of brain tryptophan and kynurenines during immune stimulation with IFN-alpha: relationship to CNS immune responses and depression. Mol. Psychiatry 15, 393-403. doi: 10.1038/mp.2009.116

Rao, J. S., Harry, G. J., Rapoport, S. I., and Kim, H. W. (2010). Increased excitotoxicity and neuroinflammatory markers in postmortem frontal cortex from bipolar disorder patients. Mol. Psychiatry 15, 384-392. doi: 10.1038/mp. 2009.47

Robson, S. C., Sévigny, J., and Zimmermann, H. (2006). The E-NTPDase family of ectonucleotidases: structure function relationships and pathophysiological significance. Purinergic Signal. 2, 409-430. doi: 10.1007/s11302-006-9003-5

Sasayama, D., Hattori, K., Wakabayashi, C., Teraishi, T., Hori, H., Ota, M., et al. (2013). Increased cerebrospinal fluid interleukin-6 levels in patients with schizophrenia and those with major depressive disorder. J. Psychiatr. Res. 47, 401-406. doi: 10.1016/j.jpsychires.2012.12.001

Shieh, C.-H., Heinrich, A., Serchov, T., van Calker, D., and Biber, K. (2014). P2X7-dependent, but differentially regulated release of IL-6, CCL2 and TNF- $\alpha$ in cultured mouse microglia. Glia 62, 592-607. doi: 10.1002/glia. 22628

Skaper, S. D., Facci, L., Culbert, A. A., Evans, N. A., Chessell, I., Davis, J. B., et al. (2006). P2X7 receptors on microglial cells mediate injury to cortical neurons in vitro. Glia 54, 234-242. doi: 10.1002/glia.20379

Sluyter, R., and Stokes, L. (2011). Significance of P2X7 receptor variants to human health and disease. Recent Pat. DNA Gene Seq. 5, 41-54. doi: 10. 2174/187221511794839219

Söderlund, J., Olsson, S. K., Samuelsson, M., Walther-Jallow, L., Johansson, C., Erhardt, S., et al. (2011). Elevation of cerebrospinal fluid interleukin-1 $\beta$ in bipolar disorder. J. Psychiatry Neurosci. 36, 114-118. doi: 10.1503/jpn. 100080

Solle, M., Labasi, J., Perregaux, D. G., Stam, E., Petrushova, N., Koller, B. H., et al. (2001). Altered cytokine production in mice lacking P2X(7) receptors. J. Biol. Chem. 276, 125-132. doi: 10.1074/jbc.m006781200

Soronen, P., Mantere, O., Melartin, T., Suominen, K., Vuorilehto, M., Rytsala, H., et al. (2011). P2RX7 gene is associated consistently with mood disorders and predicts clinical outcome in three clinical cohorts. Am. J. Med. Genet. B Neuropsychiatr. Genet. 156, 435-447. doi: 10.1002/ajmg.b.31179

Steiner, J., Bielau, H., Brisch, R., Danos, P., Ullrich, O., Mawrin, C., et al. (2008). Immunological aspects in the neurobiology of suicide: elevated microglial density in schizophrenia and depression is associated with suicide. J. Psychiatr. Res. 42, 151-157. doi: 10.1016/j.jpsychires.2006.10.013

Stokes, L., Fuller, S., Sluyter, R., Skarratt, K. K., Gu, B. J., and Wiley, J. S. (2010). Two haplotypes of the P2X(7) receptor containing the Ala-348 to Thr polymorphism exhibit a gain-of-function effect and enhanced interleukin1beta secretion. FASEB J. 24, 2916-2927. doi: 10.1096/fj.09-150862

Torres-Platas, S. G., Cruceanu, C., Chen, G. G., Turecki, G., and Mechawar, N. (2014). Evidence for increased microglial priming and macrophage recruitment in the dorsal anterior cingulate white matter of depressed suicides. Brain Behav. Immun. 42, 50-59. doi: 10.1016/j.bbi.2014.05.007

Tynan, R. J., Naicker, S., Hinwood, M., Nalivaiko, E., Buller, K. M., Pow, D. V., et al. (2010). Chronic stress alters the density and morphology of microglia in a subset of stress-responsive brain regions. Brain Behav. Immun. 24, 1058-1068. doi: 10.1016/j.bbi.2010.02.001

Viikki, M., Kampman, O., Anttila, S., Illi, A., Setala-Soikkeli, E., Huuhka, M., et al. (2011). P2RX7 polymorphisms Gln460Arg and His155Tyr are not associated with major depressive disorder or remission after SSRI or ECT. Neurosci. Lett. 493, 127-130. doi: 10.1016/j.neulet.2011.02.023

Wilkinson, S. M., Gunosewoyo, H., Barron, M. L., Boucher, A., Mcdonnell, M., Turner, P., et al. (2014). The first CNS-Active carborane: a novel P2X7 receptor antagonist with antidepressant activity. ACS Chem. Neurosci. 5, 335-339. doi: $10.1021 / \mathrm{cn} 500054 \mathrm{n}$

Yirmiya, R. (1996). Endotoxin produces a depressive-like episode in rats. Brain Res. 711, 163-174. doi: 10.1016/0006-8993(95)01415-2

Zemkova, H., Balik, A., Jiang, Y., Kretschmannova, K., and Stojilkovic, S. S. (2006). Roles of purinergic P2X receptors as pacemaking channels and modulators of calcium-mobilizing pathway in pituitary gonadotrophs. Mol. Endocrinol. 20, 1423-1436. doi: 10.1210/me.2005-0508

Zou, J., Vetreno, R. P., and Crews, F. T. (2012). ATP-P2X7 receptor signaling controls basal and TNF $\alpha$-stimulated glial cell proliferation. Glia 60, 661-673. doi: 10.1002/glia.22302

Conflict of Interest Statement: The authors declare that the research was conducted in the absence of any commercial or financial relationships that could be construed as a potential conflict of interest.

Copyright (c) 2015 Stokes, Spencer and Jenkins. This is an open-access article distributed under the terms of the Creative Commons Attribution License (CC $B Y)$. The use, distribution and reproduction in other forums is permitted, provided the original author(s) or licensor are credited and that the original publication in this journal is cited, in accordance with accepted academic practice. No use, distribution or reproduction is permitted which does not comply with these terms. 